\title{
Examining Police Agencies' Dialogic Accounting Practices in Facebook Conversations
}

\author{
QUNFANG WU, School of Information Studies, Syracuse University \\ YUN HUANG, School of Information Sciences, University of Illinois at Urbana-Champaign
}

\begin{abstract}
Police agencies have been posting regularly on Facebook and trying to use this social media platform for building community policing. However, little is known about how the public comments to police agencies' posts and how the agencies further reply to public comments on Facebook. Addressing these questions helps us understand police agencies' practices of using Facebook for supporting dialogic accounting, i.e., responding to multiple viewpoints, on this social media platform. In this work, we collected 29,928 Facebook posts of 43 municipal police agencies in the U.S. and 628,098 public comments to those agencies' posts, as well as all replies to the public comments (including replies from other public users and the agencies). We find that the agencies only replied to $907(0.1 \%)$ public comments. Our findings show that (1) the public's comments varied in diverse topics, but the agencies mainly replied to those comments that were Seeking information; (2) the agencies replied quickly when Acknowledging positive public comments; and (3) the agencies often ignored negative comments. We also discuss design implications for social media platforms to support better dialogic accounting practices.
\end{abstract}

CCS Concepts: • Human-centered computing $\rightarrow$ Empirical studies in HCI;

Additional Key Words and Phrases: Conversation, Facebook, police agency, public comment, dialogic accounting, case study

ACM Reference format:

Qunfang Wu and Yun Huang. 2020. Examining Police Agencies' Dialogic Accounting Practices in Facebook Conversations. Digit. Gov.: Res. Pract. 1, 2, Article 16 (April 2020), 17 pages.

https://doi.org/10.1145/3372022

\section{INTRODUCTION}

Social media opens up a new world of communication among diverse people, groups, and communities all around the globe. Approximately $96.4 \%$ of 553 U.S. law enforcement agencies were using social media, mostly Facebook, in 2014 according to the International Association of Chiefs of Police (IACP) survey [1]. Social media is successfully utilized to engage communities and aid crime investigations $[15,20]$. Police agencies have explored various communication strategies to disseminate information quickly and obtain information from the public $[12,15,19$,

This material is based upon work supported by the National Science Foundation under Grant No. 1464312. Any opinions, findings, and conclusions or recommendations expressed in this material are those of the author(s) and do not necessarily reflect the views of the National Science Foundation.

Authors' addresses: Q. Wu, School of Information Studies, Syracuse University, 343 Hinds Hall, Syracuse, New York, 13244-1190; email: qwu114@syr.edu; Y. Huang, School of Information Sciences, University of Illinois at Urbana-Champaign, 501 E. Daniel St., Urbana, Illinois, 61820-6211; email: yunhuang@illinois.edu.

Permission to make digital or hard copies of all or part of this work for personal or classroom use is granted without fee provided that copies are not made or distributed for profit or commercial advantage and that copies bear this notice and the full citation on the first page. Copyrights for components of this work owned by others than ACM must be honored. Abstracting with credit is permitted. To copy otherwise, or republish, to post on servers or to redistribute to lists, requires prior specific permission and/or a fee. Request permissions from permissions@acm.org.

(c) 2020 Association for Computing Machinery.

2639-0175/2020/04-ART16 $\$ 15.00$

https://doi.org/10.1145/3372022

Digital Government: Research and Practice, Vol. 1, No. 2, Article 16. Publication date: April 2020. 
26, 35]. Police agencies' social media usage may be shaped by their unique characteristics [14]. For example, police agencies' obligations are constructed by laws, policies, and legal guidelines. Thus, they mostly share "needto-know" information to inform or educate the public [11], and the information needs to be reviewed before being posted on social media [2,3]. Police agencies are short of innovating interaction strategies or performing organizational transparency on social media $[28,30]$. The public also has difficulty engaging in conversations with police agencies. On one hand, they are hesitant to share their experiences and concerns about law and order with police agencies due to the police's image as a "coercive arm of the state" [15]. On the other hand, even if the public is willing to communicate with police through social media, it is not easy for police agencies to make timely replies due to a large number of public messages [35] or satisfy a wide range of public stakeholders with varied ideological orientations. Thus, to promote two-way communication, it is important to investigate not only police agencies' social media strategies that have been studied by scholars [28, 30, 36], but also the affordance of social media platforms for the conversation between police agencies and the public.

In this article, we aim to examine the conversing process between the U.S. police agencies and the public on Facebook. We apply the dialogic accounting theoretical framework as an analytic approach [4], which can examine how police agencies develop dialogic accounting using technologies (e.g., Facebook) to foster democratic discourse and pluralistic decision-making. We collected 29,928 posts sent by 43 U.S. municipal police agencies in their official Facebook accounts in 2015; these posts received 628,098 comments from the public; 907 public comments received further replies from the agencies. We developed two code schemes to classify the public's comments and the police agencies' replies to comments. Both statistical and content analysis methods were employed to investigate how the agencies and the public conversed with each other on Facebook.

We find that most public comments expressed the public's opinions and positive support to the agencies; there were barely any negative comments made by the public. Second, not surprisingly, police agencies were only able to reply to a tiny proportion of the total public comments $(0.14 \%)$, and police agencies replied mostly to the public Seeking information related comments (56\%). In fact, it took the most time for police agencies to respond to public Sharing information comments compared to other topics (i.e., Positive comments, Seeking information, Action comments, and Negative comments). Third, the police agencies either blocked or objected to comments with the public's negative opinions or offering help, which failed to support dialogic accounting in Facebook conversations. The contribution of the article is twofold: (1) our code scheme for public comments can be utilized to identify various public values, and (2) our findings gain insights about how social media (i.e., Facebook) supports police agencies' dialogic accounting practices.

\section{RELATED WORK}

\subsection{Social Media's Support to Dialogic Accounting}

Drawing from dialogic theory, dialogic accounting serves for fostering democratic interaction and recognizing multiple stakeholders' values and viewpoints [8]. Bebbington et al. proposed a dialogic accounting theoretical framework that was a dialogic engagement approach to develop accounting technologies [4]. This framework emphasizes stakeholder engagement in governance accounting practices; that is, accounting practices must encourage discussion and enable marginalized groups to engage in the development of accounting that reflects their own values and needs [4]. Ultimately, to achieve successful dialogue between accounting institutions and the communities they serve, individuals from these communities must be permitted to participate in discussion and decision-making.

Social media can potentially support dialogic accounting by exchanging information between organizations and individuals [27]. The information transfer process enables the transparency of decision-making and stakeholder engagement [9]. Under the umbrella of the dialogic accounting framework, studies have been conducted to examine whether agencies' social media practices could support dialogic accounting in the areas of public transportation [27], police departments [17], philanthropic foundations [5], and so on.

Digital Government: Research and Practice, Vol. 1, No. 2, Article 16. Publication date: April 2020. 
Manetti et al. compared the interactions between public transportation agencies and public users on Facebook and Twitter. The results showed the interaction levels (measured by a predefined interaction ratio) on Facebook were higher than on Twitter, which indicated that Facebook supported two-way conversations more effectively than Twitter [27]. Leveraged by public transportation agencies, Facebook fostered more deliberative conversations by drawing a broader audience into the conversations; Twitter fostered more agonistic conversations by exchanging short and quick messages among different actors [27]. Another survey study on Twitter also concludes that Twitter has a limited effect on increasing police legitimacy, since it is short of reaching a broad audience and good at targeting specific public audiences [17]. Further, Bellucci et al. conducted a content analysis of the posts created by the 100 largest American philanthropic foundations and related public comments on Facebook. The goal was to evaluate whether the dialogue on Facebook created consensus shared by different stakeholders or presented discrepancies among multiple stakeholders. It concluded that Facebook supported dialogue accounting by enabling polylogic conversations [5].

In summary, prior research investigated to what degree agencies' social media accounting practices involved public stakeholders from the perspectives of breadth (e.g., interaction ratios) and depth (e.g., the tone or the topics of public comments). The dialogic accounting framework provides a good analytic tool to understand mutual interaction between government agencies and public stakeholders on social media platforms. The findings consistently suggest that Facebook is a better dialogic accounting technology than Twitter.

Based on Bebbington's dialogic accounting framework, a critical step of accounting practices is to involve various stakeholders in the decision-making process. The existing studies only focused on how to encourage or trigger multiple points of view from public stakeholders, but not how to recognize diverse interests or address their needs. It calls for further study of how agencies reply to stakeholders' comments to achieve dialogic accounting. This study will contribute to agencies' social media accounting practices by examining the back-andforth conversations between police agencies and public users on Facebook. After reviewing studies regarding police agencies' social media practices, we will propose our research questions.

\subsection{Police Agencies' Engagement with the Public on Social Media}

Social media's potential to influence a large number of people and its dynamic networking structure provide an opportunity for police agencies to propagate accurate information in a timely fashion to a large network of citizens $[14,20]$. In addition, social media can foster information interaction and build a long-term relationship between the organization and public users. More and more police agencies have adapted to social media and provided their service through it [41]. But it is challenging for some police agencies to adopt social media efficiently [7].

Police agencies' communication strategies have been examined on multiple social media platforms. Researchers identify three communication strategies on social media: Push, Pull, and Networking, which indicate the information exchange dynamics between police agencies and the public [29]. Agencies try to use a combination of these strategies to increase their collaboration with the public $[28,31]$. Prior studies have also identified factors that promote public engagement on social media. For example, one study showed that more followers can be attracted through a high posting frequency [13]. The "status" messages (which contain only text) and "photo messages" tended to receive more "likes" than the links and videos; researchers successfully built the link between the popularity of a message and the type of media used in that message on Facebook [42]. Similarly, it was found that photos and links to the photos were retweeted more as compared to the other forms of tweets on Twitter [33]; tweets that were longer or included URLs, mentions, and hashtags, were more likely to be retweeted [39].

However, little is studied about public voices and values when people comment on police agencies' Facebook posts. In the existing research, Huang et al. studied what topics different public stakeholders made and how they were associated with stakeholders' salience on Twitter [22]. Edlins and Brainard found there was inequality between police agencies' participation and public participation. Residents frequently responded to police agencies' 
initiated posts on Facebook, and they made twice the responses police agencies did [16]. Williams et al. identified police agencies' priorities in social media practices and compared them with the followers' priorities. For instance, police agencies prioritized "Accidents," "Announcements," and "Traffic" as top agenda items, whereas followers might be more concerned with issues such as "Promotion," "Crime," and "Accidents" [40].

\subsection{Agencies' Conversation Strategies on Social Media}

Social media (e.g., Facebook) enables structured back-and-forth conversations between agencies and the public. Police agencies can further serve the public by developing deeper conversations on social media. We review studies about how agencies-especially police agencies-conversed with the public in the online conversation context, including strategies and criteria [7, 16, 25, 34].

Romenti et al. developed a theoretical framework of four dialogue strategies: concertative, framing, transformative, and generative on web 2.0. By examining several crisis cases, they found that the concertative dialogue, which sought agreement or common opinions, was the most used; the transformative dialogue was the most useful strategy, which encouraged different stakeholders to share their personal opinions to gather new knowledge [34].

Researchers also explored how police agencies provided service to the public via conversations on social media platforms in accordance with their accountability and legitimacy. Lori Brainard et al. explored whether the interactions between police departments and the public on Facebook, Twitter, and YouTube were collaborative [7]. They defined the collaborative dialogue as a back-and-forth conversation that consisted of an initial question or request sent by public administrators and multiple responses from both the public and agencies. They found that the residents responded to police-department-initiated posts actively while the number of police departments' responses to the residents' posts was quite low on these platforms.

Facebook is the most promising platform for dialogue between police departments and residents. Across 46 threads on Facebook, only 3 could be regarded as indicative of collaboration and only 1 initiated by the Dallas Police Department could be considered collaborative (because the police department posted a request for help from residents that generated a multiple-response thread) [7]. Niharika Sachdeva et al. [36] examined how the police agencies replied to the public posts on their Facebook's official walls. The study found that public "Forward" posts, which needed to be forwarded to other government departments, received the most police responses, followed by "Need More Info" public posts, which needed additional information from police agencies. These responses might indicate that police made an attempt to address residents' concerns on the part of the police's accountability and made efforts to foster trust. They also used survival analysis to examine the response time of police agencies replying to the public posts. "Forward" and "Give Solutions" received quicker responses; police replied to "Need More Info" posts more slowly, since they needed more time to deal with the issues; "Thanks" posts had the longest response time due to the lower priority. Kudla et al. studied how the Toronto Police Service (TPS) replied to citizens' tweets on Twitter [25]. They found that TPS replied most often to tweets that admired TPS or that were related to community events or crime information. They argued that the foremost use of Twitter was "as a means to legitimize the organization" [25].

Based on prior studies reviewed in Section 2.2 and Section 2.3, we identified the research gap of whether and how police agencies embrace the public values and needs in back-and-forth conversations on Facebook (e.g., collaborative interaction) rather than only performing their accountability and legitimacy (e.g., informing or acknowledgment responses). Applying the dialogic accounting framework that encourages stakeholder engagement and multiple viewpoints, we will analyze the content of Facebook conversations between police agencies and public users and examine how police agencies deal with public comments to achieve dialogic accounting in Facebook conversations. We developed three research questions.

RQ1: How did the public converse with the police agencies on Facebook?

RQ2: What did police agencies reply to public comments on Facebook?

RQ3: How did police agencies leverage Facebook conversations to support dialogic accounting?

Digital Government: Research and Practice, Vol. 1, No. 2, Article 16. Publication date: April 2020. 
Table 1. Descriptive Statistics of the 43 Agencies' Posts, Public Comments, and Agencies' Replies

\begin{tabular}{lrrrrr}
\hline Dataset & Mean & \multicolumn{1}{c}{ SD } & Max & Min & Median \\
\hline \hline Agencies' Posts & 696 & 724 & 3,165 & 26 & 390 \\
\hline Public Comments & 14,587 & 28,632 & 146,432 & 58 & 3,635 \\
\hline Agencies' Replies & 23 & 28 & 150 & 1 & 19 \\
\hline
\end{tabular}

\section{METHOD}

\subsection{Data Collection}

We searched for municipal police agency Facebook accounts of cities that were either ranked among the top 50 populated cities in the U.S. (Median =622,793; $\operatorname{Max}=8,491,079 ;$ Min = 384,320) [38] or ranked among the top 10 cities for high crime rates (Median =1,443; $\operatorname{Max}=2,072 ; \operatorname{Min}=1,345$ for violent crimes per 100,000) [10]. We chose this criteria with the consideration that there would likely be more safety-related events and topics that the agencies would post on Facebook in a more populated city or a city with a higher crime rate than a less populated city or a city with a lower crime rate. By merging the two lists, we found 52 official police department accounts on Facebook and collected their posts and comments during the year 2015 by using Facepager [24], a tool for collecting posts on Facebook and corresponding comments. In our study, we particularly focused on how police agencies replied to public comments under agency-initiated posts on Facebook. Of the 52 police agencies, 43 agencies replied to public comments under their initiated posts. We filtered out the remaining 9 agencies.

In total, the 43 agencies sent 29,928 posts on Facebook and received 628,098 comments during the year 2015. However, agencies only replied to 907 public comments. Approximately each agency post received about 21 public comments, but approximately 693 public comments received one agency reply. The descriptive statistics for the 43 agencies are illustrated in Table 1.

The Facebook API provides a three-hierarchy data structure to save comments under posts, which enables our researchers to reconstruct hierarchical conversations. We first selected agencies' replies in the comments and then matched them with the responding public comments and posts using the "parentID." Applying the definition of "conversation" in Reference [7], we defined a "conversation" on Facebook as a three-level thread: the first level is the police agency initiated posts, the second level is the public user's comment, and the third level is the police agency's comment that replied to the second-level public comment. Below is an example of one conversation:

Austin Police Department's post: "Thank you [user name] for making APD Blue Santa such a huge success! \#BlueSanta https://t.co."

$\hookrightarrow$ A public user's comment: "Never received my package and my application said I was sponsored so upset that my son didn't receive anything."

$\hookrightarrow$ Austin Police Department's reply: "We have forwarded this message to the Blue Santa folks, they should be contacting you soon.”

In total, we reconstructed 907 three-level conversations. We use "conversations" to refer to the threads of posts and comments in the remainder of the article. Since several public comments received more than one reply from one agency under the post, there were 982 agency replies total in the 907 conversations.

\subsection{Analysis}

Before examining public comments, we first classified the 29,938 posts sent by 43 agencies using our annotated 6,825 police agencies' Facebook post training data [20]. We ran the SVM algorithm in Scikit-learn method. The SVM algorithm in Scikit-learn constructs a hyperplane in multidimensional space to separate classes. It 
Table 2. The Code Scheme and Samples of Public Comments

\begin{tabular}{|c|c|c|}
\hline Category & Topic & Sample Comments \\
\hline \multirow[t]{3}{*}{ Expression Related } & Positive Towards Agencies & $\begin{array}{l}\text { THANK YOU BPD!!! Any love you give our neigh- } \\
\text { borhood is greatly appreciated! }\end{array}$ \\
\hline & Negative Towards Agencies & $\begin{array}{l}\text { But how many burglaries were committed, how } \\
\text { many called to report and how many residents were } \\
\text { told "if there's no damage then there's nothing to } \\
\text { report" even if things were stolen?!?!? }\end{array}$ \\
\hline & Others & I hope that's just mud... \\
\hline \multirow[t]{2}{*}{ Information Related } & Sharing & [User name], I guess this was yesterday. \\
\hline & Seeking & What is the age cap for the test? \\
\hline Action Related & General & $\begin{array}{l}\text { Someone should start a go fund me account. I will } \\
\text { donate. }\end{array}$ \\
\hline
\end{tabular}

iteratively generates a maximum marginal hyperplane that best divides the data set into classes. The SVM classifier offers good accuracy and performs faster predictions compared to Naive Bayes algorithm. The accuracy of the 29,938 posts was $77.82 \%$.

To create a code scheme that can categorize public comments on Facebook, we utilized a two-tier code scheme for public tweets where the public mentioned police agencies on Twitter [22]. We first annotated 200 public comments based on the existing Twitter code scheme. Most public comments were able to be coded using the Twitter scheme except those public comments that expressed emotions or opinions towards the crime or the perpetrators. Therefore, we coded these types of public comments into Others. Table 2 illustrates the definitions and samples for each code. Then, we further annotated 1,186 public comments as the train data. The inter-coder agreement was $(0.85 \sim 0.96)$ for each category and the substantial agreement was $(0.73 \sim 0.86)$ for each topic. Then, we manipulated the same classification method on those 628,098 public comments by using the 1,186 manually annotated train data; the accuracy was $88.36 \%$.

- Expression-related: We coded comments that criticized the low quality of agency services or condemned the agencies into Negative. There were many comments expressing appreciation or other emotional support; we coded them to Positive. Apart from these two categories, we created one more Expression-related category, which was Others. The Others category of comments included the opinions, suggestions, and expectations of the public. These comments were neither positive nor negative towards the police agencies, but they could be utilized by the agencies to improve their services and community policing.

- Information-related: For some posts delivering or collecting information, we split them into Sharing and Seeking, respectively.

- Action-related: The Action-related posts are kept using one code, General, indicating that the category covers all kinds of action-related posts; this differs from the above Seeking topic, which regards actively looking for information rather than calling for action.

To further understand how police agencies replied to the public, we open-coded the police agencies' replies. The code scheme and samples are explained in Table 3.

In the Providing Information, Solutions, and Tips category of agency replies, the police agencies and the affiliated officers provided answers, information, tips, and instructions to the public. These comments either directed the public to a link for further information or provided the information themselves.

In the Acknowledgment category, the police agencies and their officers acknowledged public comments.

Digital Government: Research and Practice, Vol. 1, No. 2, Article 16. Publication date: April 2020. 
Table 3. The Code Scheme and Samples of Agencies' Replies to Public Comments

\begin{tabular}{|c|c|c|}
\hline Category & Topic & Sample Replies \\
\hline \multirow[t]{6}{*}{$\begin{array}{l}\text { Providing Information, } \\
\text { Solutions, and Tips }\end{array}$} & Crime & $\begin{array}{l}\text { [user name], you can be charged with Resisting Arrest under the NYS } \\
\text { Penal Law [if] someone has a warrant for their arrest from another } \\
\text { agency or incident and they resist said arrest. }\end{array}$ \\
\hline & Promotional Events & $\begin{array}{l}\text { Thank you for your support, [user name]! We are planning to } \\
\text { schedule more Coffee with a Cop events in the winter months (inside, } \\
\text { where it's warm). It's too soon to have dates on the calendar, but } \\
\text { hopefully, we will have one when you are back. }\end{array}$ \\
\hline & Recruitment & Yes, preference is given to applicants who reside in the City of Albany. \\
\hline & Lost and Found & $\begin{array}{l}\text { [user name] - No, [victim name] is still missing. Officers are still } \\
\text { hoping he's found soon. If there's an update, we'll post it as soon as } \\
\text { possible to let you know! }\end{array}$ \\
\hline & Traffic & $\begin{array}{l}\text { Roads should reopen before the morning commute. However, please } \\
\text { plan ahead for possible delays. }\end{array}$ \\
\hline & Others & $\begin{array}{l}\text { [user name], the solid black one is how the vehicle comes to us before } \\
\text { it is striped. }\end{array}$ \\
\hline \multirow[t]{2}{*}{ Acknowledgment } & Positive Comments & The thanks should really go to everyone who reported it. Thank you! \\
\hline & Negative Comments & One less person on CPD FB. We will not tolerate hate speech. \\
\hline Seeking Information & Asking Questions & Was this in the City of Atlanta or Fulton County police? \\
\hline
\end{tabular}

In the Seeking Information category, the police agencies sought more information from the public. The agencies asked for information to increase their understanding of the public problems or the criminal- and traffic-related situations of the city to facilitate their investigations.

\section{FINDINGS}

In this section, we present our findings in order of answering how the public conversed with police agencies on Facebook, how police agencies replied to public comments, and how police agencies conducted dialogic accounting practices.

\subsection{How Did the Public Converse with Agencies? (RQ1)}

To answer the first research question, we coded and classified public comments and examined whether they received agencies' replies. The results show that the public made Expression-related comments with very few Information-related and Action-related comments, but the Seeking information public comments under the Information-related category received the most replies from police agencies on average.

In the 628,098 public comments, most of them were related to expressing thoughts, and hence they were put under the Expression-related (98.17\%) category. The proportions of Information-related and Action-related comments were only $0.05 \%$ and $1.78 \%$. Of the Expression-related category, Positive comments accounted for $46.1 \%$, Negative comments for $2.1 \%$, and Others for $51.8 \%$.

When the public conversed with police agencies under agencies' Facebook posts, there were less negative comments than we found on Twitter [22]. Very few of them were negative comments, for example, " " $F$ " " the Police," one user commented on a condolence-related post. Most of the public comments were rational.

Among the 628,098 public comments, a total of 907 public comments received agencies' replies. More than half of them (64.4\%) were Information-related. $32.5 \%$ of them were Expression-related. Action-related comments were 
Table 4. Descriptive Statistics of Agencies' Replied Time Duration to Public Comments (in hours)

\begin{tabular}{cccccc}
\hline Category & Topic & N & Mean & Median & SD \\
\hline \hline Expression Related & Positive & 95 & 3.4 & 0.8 & 5.6 \\
& Negative & 16 & 6.6 & 2.9 & 7.6 \\
& Others & 149 & 5.4 & 1.4 & 6.9 \\
\hline Information Related & Sharing & 70 & 7.2 & 3.5 & 7.8 \\
& Seeking & 451 & 5.5 & 2.1 & 6.6 \\
\hline Action Related & General & 23 & 6.5 & 2.4 & 7.1 \\
\hline
\end{tabular}

only $3.1 \%$. In the topic level, the most frequent public comments were Seeking information (56.0\%) and Positive expression (11.6\%).

Compared with the overall topic distribution, Seeking information accounted for about half of the public's comments (508/56\%) in the 907 conversations. In most cases, the public sought information on recruitment and incidents being dealt with by police agencies (e.g., arrests, lost and found people, accidents, investigation of cases). They also sought information on promotional events conducted by police agencies and the equipment usage by them (e.g., cars, helicopters, cameras). Sometimes, people were also curious about the ways in which law and order were maintained by police agencies.

Due to varied responding strategies police agencies adopted, we clustered police agencies' responding patterns based on the topics of public comments to which they replied. The Elbow method indicated four as the optimal cluster number. Thus, we applied the k-means method to cluster police agencies into four clusters. The four clusters show different responding patterns of the 43 police agencies. The first cluster only contains one agency Facebook account, "Columbus Division of Police," which quite actively made responses to all topics of public comments. The second cluster includes seven agency accounts (i.e., "City of Atlanta Police Department," "City of Spokane Police Department," "Detroit Police Department," "Helena Montana Police Department," "Montpelier Police Department," "Oklahoma City Police Department," and "Santa Fe Police Public Information Officer"). Compared to the other two clusters, they responded to the public Negative and General related comments and basically balanced their replies to all topics. The third cluster contains 10 agency accounts. They replied to Seeking, Positive, Sharing, and Other related comments but seldom replied to Negative and General related comments. The remaining 25 accounts form the fourth cluster. These agencies were inactively involved in conversations and mostly only replied to Seeking information public comments. The four clusters display diverse responding preferences, which might reflect different policing goals, policies, and resources among those police agencies. We will explore what police agencies replied to public comments in the case study.

\subsection{How Did Agencies Reply to the Public? (RQ2)}

We annotated the topics of the 987 police agencies' replies and compared the responding time duration among different topics. We found that the Providing information, solutions, and tips topic accounted for more than half of the replies compared to Seeking information and Acknowledging, but the replied time duration for Positive public comments was significantly less than Others, Seeking, General, Negative, and Sharing public comments correspondingly.

The 982 agency replies were classified into three categories: Providing information, solutions, and tips to the public (667/67.9\%), Seeking information from the public (37/3.8\%), and Acknowledging public comments $(278 / 28.3 \%)$.

We also checked how quickly the agencies replied to public comments in Table 4.

Due to the highly right-skewed distribution, a Kruskal-Walls test was performed to assess whether these six topics were identical or not. The result implies that not all the medians were equal $(H=19.37, d f=5, p<0.01)$.

Digital Government: Research and Practice, Vol. 1, No. 2, Article 16. Publication date: April 2020. 
Then, 15 sets of experiments were carried out to compare the median values pairwise. We find that the time duration in which positive comments were replied to was significantly different from other topics $(p<0.05)$. However, the remaining five topics had no significant difference.

As shown in Table 4, the least time taken by police agencies was in replying to public Positive comments towards them $($ Mean $=3.4$, Median $=0.75)$. It is possible that these comments mostly needed simple acknowledgments from the agencies, thus the response time was the least.

Public comments in the Others category, which were composed of neutral opinions and suggestions from the public to the police agencies, also needed less response time (Mean $=5.35$, Median $=1.36)$.

The response time to Seeking information comments was larger (Mean $=5.47$, Median $=2.1)$. This was probably because the police agencies had to search for relevant information and provide the correct answers to the public.

In the General topic, the public called for action regarding crimes, traffic conditions, and promotional events. This type of comment did not pose any pressing need for the agencies to take urgent action, thus the response time to them was larger $($ Mean $=6.46$, Median $=2.44)$ than the comments in the topics of Seeking information and Others.

In the Sharing topic, the public shared information with the police agencies. The delay in responding to this type of comment (Mean $=7.18$, Median $=3.47$ ) could be due to the time taken in verifying the information and even looking for additional information.

The least number of comments that received police agencies' responses were the Negative comments (18 out of 982 total public comments). The response time duration to them was the largest on average (Mean $=6.6$, Median $=2.88)$. Half of them were replied to in three hours.

\subsection{Police Agencies' Dialogic Accounting Practices in Facebook Conversations (RQ3)}

After annotating the agencies' replies in the 907 conversations, we find that more than half (67.9\%) were Providing information, solutions, and tips to the public, where police agencies were performing their obligations and providing services to the public. According to the dialogic accounting framework, researchers argued that agencies should consider multiple viewpoints and values, especially negative voices, when conversing with the public [4]. Though acknowledging public comments and collecting information from the public may promote public engagement, it does not mean that police agencies handle various values and viewpoints to support dialogic accounting. For example, among the 907 conversations, there were only 18 (2\%) Negative public comments acknowledged by agencies compared to other types of public comments.

To examine whether Facebook conversations between police agencies and public-supported dialogic accounting, we conducted case studies with all public comments (both replied to and non-replied-to by agencies) and police agencies' replies under the 907 posts. Particularly, we reviewed (1) how the public expressed their opinions regarding the original posts and (2) how police agencies coordinated with those public comments in their replies.

Overall, more than half of these comments needed brief appreciation or acknowledgment and did not show the possibility of further discussion. However, we found that many expressed their diverse opinions or tried offering help, which signaled further discussion between police agencies and the public to eliminate misunderstanding, emphasize consensus, and so on. By probing public comments, we demonstrate three types of cases in the following section: (1) negative public opinions, (2) positive public opinions, and (3) public offering help. We also find that police agencies conversed well with public positive opinions but did not deal with public negative opinions or offer help well, especially when being criticized about the misuse of social media.

4.3.1 Negative Public Opinions. On scrutinizing the public comments containing negative emotion, we find that the negative comments posed doubt or dissatisfaction regarding the police agency's actions or expressed complaints about government in general.

Digital Government: Research and Practice, Vol. 1, No. 2, Article 16. Publication date: April 2020. 
The police agencies tended to apologize and provide the public with detailed regulations. For example, some of the negative comments from the public were about crimes going on in the city, so the agencies tried to alleviate the public by informing them of the crime-related laws, strategies, and methods.

\begin{abstract}
Albany Police Department's post: "Daily Arrest Reports From Over the Weekend: http://www.albanyny...”

$\hookrightarrow$ A public user's comment: "How can you ONLY be charged with resisting arrest? Did they accuse him, taze him... and find out it wasn't a valid reason? Just curious. Usually something will accompany a charge like this. You can't arrest someone without a reason ... ehhhh?"

$\hookrightarrow$ Albany Police Department's first reply: "Loren, you can be charged with Resisting Arrest under the NYS Penal Law is someone has a warrant for their arrest from another agency or incident and they resist said arrest."

$\hookrightarrow$ Albany Police Department's second reply: "No, the charges originate with the agency who issues the warrant. For example, let's say you commit a crime in New York City and the NYPD issues a warrant for your arrest. If you are located here in Albany by a member of our department, we arrest you for the warrant and turn you over to the NYPD. If you resist while officers in Albany are trying to take you into custody for the NYPD warrant, you'll be charged with just resisting because the resisting arrest occurred in Albany. In this case, the warrant was from NYS Parole. Hope this helps." (Crime Related)
\end{abstract}

However, the public also showed their discontent with police agencies using social media inappropriately. The public criticized that police agencies reported fake facts, lacked "culture awareness," or only used social media as a marketing or propaganda tool. For this type of comment, police seldom responded.

For example, one public comment questioned a fake report from a post from Oklahoma City Police Department and said that the police officer did not deal with the situation professionally. The police agency did not reply to it.

Oklahoma City Police Department's post: "Shortly before 6:00 last night, police responded to a call of a drowning child in the 3300 block of NW 36th. A 3-year-old boy was discovered at the bottom of a swimming pool. After being pulled from the pool, a family friend, Katy Reddick, began CPR on the child just as the officer was arriving. The child wasn't breathing and had no pulse. Officer Steven Cholity took over CPR until the child began coughing and crying. ... Great job Officer Cholity and Ms. Reddick!"

$\hookrightarrow$ A public user's comment: "Let's be true and honest here, the real hero is the friend who did CPR. The cop just tried to take credit, maybe because of all the bad things that cops keep doing across the nation. That cop could have put the child in danger, by stopping the family friend from doing CPR, just so he can take over."

In the example below, the Denver police department posted an announcement in which the "cultural awarenss" offended public users. One user expressed dissatisfaction with the marketing department of the police agency.

Denver Police Department's post: "TELL YOUR KIDDOS Starting tomorrow, Denver Police will be actively enforcing Denvers curfew ordinance. The ordinance prohibits youth, 17 years of age or younger, from being in a public place or on public property from 11 PM to 5 AM, Sunday through Thursday, and 12 AM to 5 AM Friday and Saturday. "

$\hookrightarrow$ A public user's comment: "DPD why do all of the children in you art appear to be Black? This is not a good look at all. I am sure there are non Black children out after curfew, as I have seen them myself. You all should work on your marketing departments cultural awareness."

The comment below revealed a typical kind of negative opinion toward police. The negative impression was actually triggered by other events or reasons but posted under a "thank you" post. Also, this comment argued that the police agency's official account was used as a propaganda tool rather than a communication or servicing channel.

Digital Government: Research and Practice, Vol. 1, No. 2, Article 16. Publication date: April 2020. 
City of Atlanta Police Department's post: "Thank you for all the alerts about this Facebook poster. Once we received all your messages, we alerted our Homeland Security Unit who worked all day to locate this person. Once she was found to be living in East Point, we turned the case over to East Point. Thanks again!"

$\hookrightarrow$ A public user's comment: "So sad over posts... no wonder people rioting and killing cops... you got a dude shooting up a movie theater killing women and kids.. cops safely escort him to jail... another man runs from a traffic ticket and is gunned down... people are gonna start putting 2 and 2 together... Police should be policing themselves... instead of causing propaganda about meaningless posts."

There is another public negative comment. It strongly doubted that the police agency's shooting investigation post was to "hype" themselves on social media.

City of Atlanta Police Department's post: "Below is the official statement regarding the officer involved shooting.... The Officers are scheduled to give their statements to investigators early next week. This is in accordance with best practices related to the investigation of Officer involved shootings as established by the International Association Chief of Police."

$\hookrightarrow$ A public user's comment: "I say we pull all police and innocents out of the riot areas and just let them beat each other to death. the only reason they're "protesting" is to get the media hype. They have no clue what or why they are protesting."

The instances above indicate that police agencies need to be better prepared for reacting to the negative effects of using social media. It suggests police agencies should know how to post appropriately on Facebook but also be always ready to converse with any potential negative opinions. Only the Columbus Division of Police directly addressed such types of public comments with a very brief response. It seems that the police agency did not want the use of offensive words on such an important post.

Columbus Division of Police: "DUMB CRIMINAL? On 11/2 at 9:11PM a strong robbery occurred at Morse $R d \&$ Cleveland Ave. The injured victim supplied a description of the suspect \& direction of travel..." $\hookrightarrow$ A public user's comment: "Columbus Police....Please delete this entire post. It's bringing nothing but tension and race remarks."

$\hookrightarrow$ Columbus Division of Police's reply: “One less person on CPD FB. We will not tolerate hate speech.”

4.3.2 Public Positive Opinions. Public comments contributed many opinions or suggestions in positive emotion. Though not all of them were replied to, the police agencies provided information or services when conversing with the public. Below, we provide three cases of public positive opinions: improving services, forwarding requests, and showing care.

Improving Services. In most of the conversations, the police agencies were seeking follow-up information from the public. For example, City of Atlanta Police was trying to reach out to an individual user for more details beyond the public conversations.

City of Atlanta Police Department: “Safety tip: Don't be afraid to call 9-1-1. Citizens are also encouraged to be aware of surroundings, and call 9-1-1 to report any suspicious activity. Remember the Department's 'See Something, Say Something' campaign to encourage vigilance for criminal activity."

$\hookrightarrow$ A public user' comment: "I totally agree and will continue doing so, but twice now I've called 911 and been treated poorly for calling.... This all happened in Midtown-corner of North Ave and Piedmont. How do they screen for 911 operators?"

$\hookrightarrow$ City of Atlanta Police Department's reply: "XXX (the user name) can you message us some contact info for you?" 
During the conversations, the agencies showed great interest in hearing public comments or suggestions on improving services. For example,

City of Atlanta Police Department's post: “\#Zone4 Coffee with a Cop next Tuesday! foin Chief George Turner, Major Vincent Moore and local officers at the IHOP located at 2841 Greenbriar Pkwy SW, Atlanta, GA 30331."

$\hookrightarrow$ A public user's comment: "Anything similar planned for Zone 2?"

$\hookrightarrow$ City of Atlanta Police Department's reply: “We can! Location suggestion?”

Similarly, the public and the agencies conversed on different ways to look at certain safety issues.

Santa Fe Police Public Information Officer (PIO)'s post: "Missing: Evelyn Becerra 14 years old 5'4", 125 lbs. Brown Hair with light streaks, Brown Eyes Unknown Clothing Description Ran away on 04/01/2015 If you have any information please call SFPD at 505-428-3710"

$\hookrightarrow$ A public user's comment: "Maybe you guys should make sure her home life is ok Maybe she doesn't want to be there for a reason idk I think that's a red flag if someone is constantly running away from home. Maybe she just doesn't know who to talk to about it."

$\hookrightarrow$ Santa Fe Police Public Information Officer (PIO)'s reply: "We always look into the family situation in cases such as this. Thank you for the concern."

In addition, the agencies expressed their interest in exchanging ideas with the public regarding how to address safety issues or improve public health.

City of Phoenix Police Department's post: "In a highly unusual collaboration, every broadcast TV station and most radio outlets across Arizona will air simultaneously a 30-minute commercial-free investigative report produced by Arizona State University student journalists on the growing perils of heroin and opioid use..."

$\hookrightarrow$ A public user's comment: "That's fantastic! I have 14 years clean from Meth and I think awareness is key!"

$\hookrightarrow$ City of Phoenix Police Department's reply: "Sara Davis, that's wonderful. What things do you think people should be aware of, but generally aren't when it comes to drug addiction?"

Forwarding Information. Following is the sample conversation in which the police agency forwarded the public query and concern to the relevant department:

Helena Montana Police Department's post: “... Here are the report notes Wednesday and Thursday here in Helena: 11/24/15 @ 10:14am An officer investigated a theft from a business in the 2900 blk of North Sanders Street. ...”

$\hookrightarrow$ A public user's comment: "So there's a dude in clyde park Montana (I don't know how far it is from you guys) but he's basically admitting to being the next planned parenthood shooter."

$\hookrightarrow$ Helena Montana Police Department's reply: "Kitty Allister, can you email me your name, address, phone number? I'll forward it on to the sheriff's department so they can get in touch with you. Email me @cstinson@helenamt.gov.”

Showing Care. The public also shared information about police officers, criminal suspects, criminal- and trafficrelated violations, their own experiences, and identified people. They also shared information on lost and found people, animals, and vehicles. When replying to these comments, the police agencies tended to validate the shared information or share more information with the public to resolve any confusion or assure them that further action would be taken. Here are some examples:

Digital Government: Research and Practice, Vol. 1, No. 2, Article 16. Publication date: April 2020. 
Montpelier Police Department's post: "\#Throwbackthursday is back! And these 50s era Montpelier officers are ready for anything! Did you know during this period MPD only had one police car? The only radio available to officers was in this cruiser and they would alternate between time at the police station, in the car, and on foot patrol. The Chief of Police during this time was Frank Baldwin."

$\hookrightarrow$ A public user's comment: "I think Frank Baldwin was an earlier chief, could have been George Conner. Art Mcellon was chief about that time."

$\hookrightarrow$ Montpelier Police Department's reply: "Robert, that's correct, there was a turnover in the mid 50's. Chief Connor is in a future post."

Similar responses were found in other agencies' Facebook posts. For example:

City of Charleston Police Department's post: "There are many ways to contact Charleston Police and provide tips of the shooting of 5-year-old Tyreik Gadsden and other crimes: ..."

$\downarrow$ A public user's comment: "Hi... I read that an arrest was made of the monster who dct taped the dog Caitlyns mouth together so tightly she nearly died ... and laughed about it to the previous owner... Please ... please make sure this sadistic monster is jailed.. and you have to wonder what is next on his list ... a child... a woman ????? ... Along with millions of people around the world on social media we are hoping this creep is punished ......"

$\hookrightarrow$ City of Charleston Police Department's reply: "Many thanks for your comment, but this happened in a neighboring jurisdiction."

There were some comments in which public members asked police agencies to take action to improve their working procedures and ways of sharing information on social media. This type of comment was confirmed by the police agencies. An example is as follows:

Lincoln Police Department's post: "Lincoln police are investigating nine armed robberies committed at local businesses over the past nine days. Though descriptions vary, most are committed by a white male, 20 s, 6'0" tall with a thin build. We encourage anyone with information to call LPD 402.441 .6000 and ask to speak with a criminal investigator or submit information anonymously via Lincoln Crimestoppers." $\hookrightarrow$ A public user's comment: "how about we get some pictures."

$\hookrightarrow$ Lincoln Police Department's reply: "Once we have quality images, they will be heavily distributed. For now, this is what we are working with..."

4.3.3 Public Offering Help. Other than negative and positive comments, the public also voluntarily offered online and offline help. As shown in the examples below, the public offered help by sharing fund-raising links or sharing free food information. But these comments did not receive acknowledgment or validation from the police agencies.

Little Rock Police Department's post: "In honor of National Police Week, officers say a prayer before hitting the streets of the City of Little Rock. Thank you for your service to this city and its citizens!" $\hookrightarrow$ A public user's comment: "The Arkansas Deputy with fohnson County who lost his life yesterday now has a Gofundme link. I'd like to report his son DID walk for graduation last night surrounded by a Sea of Blue!! He was honored with a standing ovation \& not a dry eye!! Please, please copy \& share this link!! [link]"

IMPD News Police Department's post: "Had a run to check welfare on this gentleman in the white shirt, This is Edward. Edward has stage 4 cancer and gets little to nothing of a check on the first of every month and had been denied local assistance. All the gentlemen around him pitched in and took care of his bill. He's paid up till the first of the month." 
$\sqcup$ A public user's comment: "Please let Edward know about this ministry. Fohn \& Ann work every week to feed the hungry \& homeless of downtown Indianapolis. [link]"

$\hookrightarrow$ A public user's comment: "Don't [know] where he lives but our church has a food pantry the 2nd Sat of each month from 9 to 11. We are St.Fohns Episcopal church on W 30th St Speedway. We also have the food pantry the 4th Wed in the eve not sure of the time."

\section{DISCUSSION}

In this section, we reflect on our findings from the public value theory and the dialogic accounting framework. We discuss that the topics of public comments demonstrate different public values. We also reflect on whether police agencies' Facebook conversations supported dialogic accounting. Last, we discuss the limitations and future work.

\subsection{Identifying Public Values in Public Comments}

Platforms' features may influence the public's behavior and lead to various participation forms [23]. Our findings reveal that the public actively supported the police agencies by making positive comments and came up with suggestions that police agencies could adopt for improving their services; there were very few negative public comments. However, our prior work found that when public users mentioned the police agencies on Twitter, 16.75\% (2,645 out of 15,785) of their tweets were negative towards the agencies [22]. This could be due to the fact that the Facebook comments we analyzed were directly addressing the agencies' Facebook posts; as compared to the Twitter platform, the public tweets mentioning the agencies were not displayed on the agencies' Twitter pages.

Identifying public values in services can enhance public trust and satisfaction [18]. According to the public value theory [18], public satisfaction and trust in agencies were driven by three factors: "a sense of being wellinformed," "a sense of personal control" in one's life, and "a sense of influence." Our study developed a two-tier scheme to classify public comments. The categories and topics of public comments help identify public values in their social media engagement. That the public made Seeking information comments indicates a need for being well-informed. Our results show that Seeking information comments were the most likely to receive agencies' replies. Public posting Expression-related, Action-related, and Sharing information comments expressed their intention of making an influence on public affairs, especially those public users who made negative comments (RQ1). These negative comments strongly requested changes or improvement of police agencies' services. The sense of personal control needs a flexible and responsive service and cannot be reflected by a certain topic of public comments. But our result about the responding time duration might explain the public experience of personal control; that is, police agencies were more responsive when responding to Positive comments compared to other topics (RQ2). Our code scheme can be used to categorize the public's comments so police agencies can strategize their services on social media.

\subsection{Facebook Conversations for Supporting Dialogic Accounting}

Prior studies examined conversations on social media between agencies and the public in terms of "collaborative" [7], "serviceable" [36], or "responsive" [36]. Those studies focused more on agencies' accountability and legitimacy. For example, serviceable public comments were defined by the official obligation and annotated by the police officers [36]. In contrast, the dialogic accounting framework takes social media practices as a democratic discourse. It suggests engaging multiple viewpoints from stakeholders and facilitating broader debates rather than obtaining incontrovertible answers [6,32]. Studies that applied the dialogic accounting framework concluded that Facebook facilitated a broader and more democratic interaction between agencies and the public $[5,17,27]$. Our study does find that public users expressed their various values in Facebook conversations (i.e., Expression-related, Information-related, and Action related).

Digital Government: Research and Practice, Vol. 1, No. 2, Article 16. Publication date: April 2020. 
In addition, we also gained new knowledge about how police agencies tackled public comments in back-andforth Facebook conversations. Police agencies deployed accountability and legitimacy by Providing information, solutions, and tips to the public, which took the largest proportion (67.9\%) compared to Acknowledging the public (28.3\%) and Seeking information from the public (3.8\%) in agencies' replies (RQ2). But the proportion of Acknowledging shows a tendency that police agencies also expanded their effort to emotion-related public comments, especially acknowledging positive comments, with the purpose of fulfilling dialogic accounting in Facebook conversations.

First, the Positive public comments received the shortest response time duration, followed by neutral public opinions or expectations in the Other category (RQ2). The results are different from Sachdeva's study where Indian police agencies took information-related public comments (i.e., "Forward" and "Give solutions") as the highest priority and emotion-related comments (i.e., "Thanks") as the lowest priority [36]. Second, in the case studies, police agencies developed good conversations with the public when they expressed positive opinions, i.e., improving services, forwarding information, and showing care (RQ3). It seems easier for agencies to fulfill dialogic accounting when they shared consistent goals and values with the public.

However, when dealing with negative public opinions, police agencies tried to make different stances or values invisible by overlooking those public comments (RQ3). It was possible that police agencies failed to reply to public negative opinions or offering help given a large amount of public comment influx in a short time [37]. Besides, some public negative comments not only criticized police agencies' service but also challenged the way agencies utilized social media. The police agencies might choose to neglect those negative comments with the purpose of building a good image on social media platforms and to fulfill higher priorities on their agendas [40]. The finding indicates that Facebook conversations between police agencies and the public did not support dialogic accounting when the public topics were negative or less related to the policing obligations.

The current Facebook conversation structure or the Facebook wall is easily inundated and makes dialogue agonistic, short of supporting dialogic accounting practices. To address the challenge, Romenti's four dialogue strategies could be considered to embrace pluralistic directions on social media [34]. Police agencies tended to develop concertative dialogue that was to seek agreement or common opinions [34]. In fact, transformative dialogue, which is to create a participatory environment to encourage different stakeholders to share personal opinions, can be leveraged to gather new perspectives or knowledge and thus build trust. Facebook features can be designed to support free conversations with specific topics. Natural language processing tools can be developed to identify new or opposite opinions.

\subsection{Limitations and Future Work}

In our data set, we collected 982 agency replies that accounted for only $0.1 \%$ of the 628,098 public comments. The case study results may not be generalizable to the U.S. police agencies' replying behavior. Besides, we only considered the 52 official police department accounts that were either the most populated cities or with the highest crime rates. And we only collected the Facebook posts of those U.S. police agencies that received public responses. Our findings may not reflect the social media practices of those agencies with different population or crime-rate characteristics and cannot be applied to agencies of other countries. For instance, police agencies in less populated cities or with lower crime rates may post fewer crime-related topics and converse more frequently with their smaller number of public followers. In addition, this study was conducted using Facebook data. How police agencies and the public communicated may be different on other social media platforms [21]. We will explore how the police agencies converse with the public on other social media platforms; for example, whether police agencies deal with negative public comments the same way on Twitter and YouTube as on Facebook. Given the different information sources and design features, there might be various strategies used by the police agencies.

Besides, we only collected and analyzed data from the social media platform. Police agencies' daily practices on social media (e.g., Facebook and Twitter) might be influenced by the people who operated the official accounts and their policy. For example, they might have deleted negative public comments, which would bias our current 
result. To further investigate the interaction, we plan to interview police agencies or officers about how they manage the online official accounts and the criteria of replying to public comments.

The Facebook API does not provide the hierarchical information for comments after the third level. Thus, we cannot reconstruct deeper level comments in the conversations based on the current data structure. Besides, we have no access to the historical number of followers for these agencies' accounts. Without this information, we cannot evaluate the level of interaction between agencies and their followers.

\section{CONCLUSION}

In this article, we presented our research exploring the ways in which the public commented on the police agencies' posts and how the agencies replied to the public on Facebook. We developed two code schemes for categorizing public comments and agencies' replies to understand their interactions on social media. Our findings show that, often, the public shared their concerns, opinions, and positive acknowledgments on the police agencies' posts while police agencies replied more to the Seeking information public comments as compared to other categories. It is also deduced that there was a much lesser number of Negative public comments. Then, we identify the timely responsiveness of the police agencies on various categories of public comments. We further conducted case studies to investigate police agencies' dialogic accounting practices in Facebook conversations. The results show that police agencies overlooked public negative opinions or voluntary help while they developed deeper conversations to interact with the public's positive viewpoints. Our work contributes on theoretical and practical knowledge to police agencies' dialogic accounting practices on social media.

\section{ACKNOWLEDGMENTS}

We thank Saurabh Gupta, Qiuyan Liu, Tian Xu, and Shuo Geng for their input to the data analysis.

\section{REFERENCES}

[1] International Association of Chief's of Police Center for Social Media. 2014. Survey on Law Enforcement's Use of Social Media. Retrieved from http://www.iacpsocialmedia.org/Resources/Publications/2014SurveyResults.aspx.

[2] Anne Arundel County Police Department. 2015. The Anne Arundel County Police Department Public Information/Media Policy/Public Information Act Request. Retrieved from http://www.aacounty.org/Police/RulesRegs/Sections20-24/2420PublicInfo-MediaPolicy.pdf.

[3] Erie Police Department. 2010. Erie Police Department Media Relations Policy. Retrieved from https://www.erieco.gov/ DocumentCenter/Home/View/574.

[4] Jan Bebbington, Judy Brown, Bob Frame, and Ian Thomson. 2007. Theorizing engagement: The potential of a critical dialogic approach. Account. Audit. Accountab. F. 20, 3 (2007), 356-381.

[5] Marco Bellucci and Giacomo Manetti. 2017. Facebook as a tool for supporting dialogic accounting? Evidence from large philanthropic foundations in the United States. Account. Audit. Accountab. 7. 30, 4 (2017), 874-905.

[6] Gordon Boyce. 2000. Public discourse and decision making: Exploring possibilities for financial, social and environmental accounting. Account. Audit. Accountab. 7. 13, 1 (2000), 27-64.

[7] Lori Brainard and Mariglynn Edlins. 2015. Top 10 US municipal police departments and their social media usage. Amer. Rev. Pub. Admin. 45, 6 (2015), 728-745.

[8] Judy Brown. 2009. Democracy, sustainability, and dialogic accounting technologies: Taking pluralism seriously. Crit. Persp. Account. 20, 3 (2009), 313-342.

[9] Judy Brown and Jesse Dillard. 2015. Opening accounting to critical scrutiny: Towards dialogic accounting for policy analysis and democracy. F. Compar. Policy Anal. Res. Pract. 17, 3 (2015), 247-268.

[10] Thomas C. Frohlich, Alexander Kent, and Alexander E. M. Hess. 2014. The Most Dangerous Cities in America. 24/7 Wall St. Retrieved from http://247wallst.com/special-report/2014/11/11/the-most-dangerous-cities-in-america-4/2/.

[11] Joshua Chanin and Salvador Espinosa. 2016. Examining the determinants of police department transparency: The view of police executives. Crim. Fust. Policy Rev. 27, 5 (2016), 498-519.

[12] Steven Chermak and Alexander Weiss. 2005. Maintaining legitimacy using external communication strategies: An analysis of policemedia relations. F. Crim. Fust. 33, 5 (2005), 501-512.

[13] Belle Beth Cooper. 2013. 7 Powerful Facebook statistics you should know for a more engaging Facebook page. The Buffer Blog. Retrieved from https://buffer.com/resources/7-facebook-stats-you-should-know-for-a-more-engaging-page.

[14] Jeremy Crump. 2011. What are the police doing on Twitter? Social media, the police, and the public. Policy Internet 3, 4 (2011), 1-27.

Digital Government: Research and Practice, Vol. 1, No. 2, Article 16. Publication date: April 2020. 
[15] Sebastian Denef, Petra S. Bayerl, and Nico A. Kaptein. 2013. Social media and the police: Tweeting practices of British police forces during the August 2011 riots. In Proceedings of the SIGCHI Conference on Human Factors in Computing Systems. ACM, 3471-3480.

[16] Mariglynn Edlins and Lori A. Brainard. 2016. Pursuing the promises of social media? Changes in adoption and usage of social media by the top 10 US police departments. Information Polity 21, 2 (2016), 171-188.

[17] Stephan G. Grimmelikhuijsen and Albert J. Meijer. 2015. Does Twitter increase perceived police legitimacy? Pub. Admin. Rev. 75, 4 (2015), 598-607.

[18] Mike Grimsley and Anthony Meehan. 2007. e-Government information systems: Evaluation-led design for public value and client trust. Europ. J. Inf. Syst. 16, 2 (2007), 134-148.

[19] Thomas Heverin and Lisl Zach. 2010. Twitter for city police department information sharing. Proc. Assoc. Inf. Sci. Technol. 47, 1 (2010), $1-7$.

[20] Yun Huang, Sen Huo, Yaxing Yao, Niu Chao, Yang Wang, Jennifer Grygiel, and Steve Sawyer. 2016. Municipal police departments on Facebook: What are they posting and are people engaging? In Proceedings of the 17th International Digital Government Research Conference on Digital Government Research. ACM, 366-374.

[21] Yun Huang and Qunfang Wu. 2018. Understanding interactions between municipal police departments and the public on Twitter. In Proceedings of the International Conference on Information. Springer, 37-46.

[22] Yun Huang, Qunfang Wu, and Youyang Hou. 2017. Examining Twitter mentions between police agencies and public users through the lens of stakeholder theory. In Proceedings of the 18th International Conference on Digital Government Research. ACM, 30-38.

[23] Yun Huang, Qunfang Wu, Xing Huang, and Jennifer Bort. 2017. A multiplatform investigation of law enforcement agencies on social media. Inf. Polity 22, 2-3 (2017), 179-196.

[24] Till Keyling and Jakob Jünger. 2014. Facepager: A Tool for Gathering Facebook Data. Retrieved from http://snurb.info/node/1861.

[25] Daniel Kudla and Patrick Parnaby. 2018. To serve and to tweet: An examination of police-related Twitter activity in Toronto. Soc. Media+ Society 4, 3 (2018), 2056305118787520.

[26] Sheena Lewis and Dan A. Lewis. 2012. Examining technology that supports community policing. In Proceedings of the SIGCHI Conference on Human Factors in Computing Systems. ACM, 1371-1380.

[27] Giacomo Manetti, Marco Bellucci, and Luca Bagnoli. 2017. Stakeholder engagement and public information through social media: A study of Canadian and American public transportation agencies. Amer. Rev. Pub. Admin. 47, 8 (2017), 991-1009.

[28] Albert Meijer and Marcel Thaens. 2013. Social media strategies: Understanding the differences between North American police departments. Gov. Inf. Quart. 30, 4 (2013), 343-350.

[29] Albert Jacob Meijer and René Torenvlied. 2016. Social media and the new organization of government communications: An empirical analysis of Twitter usage by the Dutch police. The American Review of Public Administration 46, 2 (2016), 143-161.

[30] Ines Mergel. 2012. The social media innovation challenge in the public sector. Inf. Polity 17, 3, 4 (2012), 281-292.

[31] Ines Mergel. 2013. Social media adoption and resulting tactics in the US federal government. Gov. Inf. Quart. 30, 2 (2013), 123-130.

[32] Pala Molisa and Bettina Wittneben. 2008. Sustainable development, the clean development mechanism, and business accounting. In Economics and Management of Climate Change. Springer, 175-192.

[33] Patricia Redsicker. 2014. Social photos generate more engagement: New research. Social Media Examiner 50, 1 (2014).

[34] Stefania Romenti, Grazia Murtarelli, and Chiara Valentini. 2011. A theoretical framework for carrying on dialogue with social media stakeholders during crisis situations. In Proceedings of the International Conference on Crisis Communication at the Beginning of the 21st Century.

[35] Niharika Sachdeva and Ponnurangam Kumaraguru. 2015. Social networks for police and residents in India: Exploring online communication for crime prevention. In Proceedings of the 16th International Conference on Digital Government Research. ACM, 256-265.

[36] Niharika Sachdeva and Ponnurangam Kumaraguru. 2017. Call for service: Characterizing and modeling police response to serviceable requests on Facebook. In Proceedings of the 2017 ACM Conference on Computer Supported Cooperative Work and Social Computing. 336-352.

[37] Niharika Sachdeva and Ponnurangam Kumaraguru. 2017. Social Media and Policing: Computational Approaches to Enhancing Collaborative Action between Residents and Law Enforcement. Ph.D. Dissertation. IIIT-Delhi.

[38] U.S. Census Bureau. 2014. Top 50 Cities in the U.S. by Population and Rank. Retrieved from https://www.infoplease.com/us/us-cities/ top-50-cities-us-population-and-rank.

[39] Bob Van De Velde, Albert Meijer, and Vincent Homburg. 2015. Police message diffusion on Twitter: Analysing the reach of social media communications. Behav. Inf. Technol. 34, 1 (2015), 4-16.

[40] Christine B. Williams, Jane Fedorowicz, Andrea Kavanaugh, Kevin Mentzer, Jason Bennett Thatcher, and Jennifer Xu. 2018. Leveraging social media to achieve a community policing agenda. Government Information Quarterly 35, 2 (2018), 210-222.

[41] Matthew L. Williams, Adam Edwards, William Housley, Peter Burnap, Omer Rana, Nick Avis, Jeffrey Morgan, and Luke Sloan. 2013. Policing cyber-neighbourhoods: Tension monitoring and social media networks. Polic. Soc. 23, 4 (2013), 461-481.

[42] Bei Yu, Miao Chen, and Linchi Kwok. 2011. Toward predicting popularity of social marketing messages. In Proceedings of the International Conference on Social Computing, Behavioral-Cultural Modeling, and Prediction. Springer, 317-324.

Received February 2019; revised October 2019; accepted November 2019

Digital Government: Research and Practice, Vol. 1, No. 2, Article 16. Publication date: April 2020. 